\title{
Like a chameleon: The polychromatic virtue of dynamic brands
}

\begin{tabular}{|r|l|}
\hline Journal: & Journal of Product \& Brand Management \\
\hline Manuscript ID & JPBM-10-2017-1621.R4 \\
\hline Manuscript Type: & Regular Paper \\
\hline Keywords: & Logo design, Colour, Brand identity, Dynamic brands \\
\hline \multicolumn{2}{|l}{} \\
\hline
\end{tabular}

SCHOLARONE ${ }^{m}$

Manuscripts 


\title{
Like a chameleon: The polychromatic virtue of dynamic brands
}

\begin{abstract}
Purpose

The main objective for this paper was to identify the chromatic approaches in dynamic brand identities, describing and analysing new trends, patterns or shared strategies which seem to be taking place, renunciating the consistent use of corporate colours in some brands.

Design/methodology/approach

The research consisted of a qualitative visual content analysis, based on the comparison and scrutiny of 50 dynamic visual identities, verifying the changes that their colours would undergo in their numerous forms of representation and the symbolic associations these would carry. This analysis was performed using three different studies.

\section{Findings}

The results show that colour in dynamic brands does not follow any consistent pattern regarding its application and none of the most common colour harmonies seem to be an obvious strategic preference.

\section{Practical implications}

This research provides insights for 1) brand managers to look at how this dynamic positioning can be successfully implemented without affecting recognition whilst establishing or maintaining customer loyalty, and 2) brand for designers and marketers to clarify how brand guidelines will explain the usage of such colourful approaches.

Originality/value

This paper is a contribution to the knowledge of how a traditional visual element such as colour is being combined, deconstructed and reassembled in the context of modern visual identities. Three patterns are identified, and two of them draw attention to the apparent unnecessity of colour consistency and the way this may affect the relevance of colour in transmitting certain meanings.
\end{abstract}

Keywords: Logo design, brand identity, colour, dynamic brands Article classification: Research paper

\section{Introduction}

For decades, visual identities have been structured around their Visual Identity Systems (VIS), which forms a unit extremely important for brands to standardise their visual identity usage and application, ensuring consistency and recognition. However, the current infocommunication environment - which is defined by Passarelli et al. (2014) as the context immersed in digital technologies that create, use and store the information that will be utilised in the communication processes for the exchange of messages - brought participation, interaction, appropriation, motion, mutability and ubiquity to many different aspects of human life, and is also changing the way brands are used as communication instruments. Brands now adapt to the context in which they operate, where they know their audiences will be and, more than ever before, brands are currently allowed a certain amount of flexibility to develop, which is inherent to a constantly evolving process. Grounded in this hypermodern perspective (Lipovetsky, 2007), the brand is assumed to be something that is much more than a form of differentiation, and instead to be something that is intrinsically 
part of an identity, liable to convey a massive complexity of contextual meanings, many of them potentially unexpected and depending on pure serendipity.

Therefore, for the dynamic and social processes that brands more recently became, the VIS can no longer be graphically fixed: brands do change their visual elements over shorter or longer periods of time, and some behave in completely random ways (Felsing, 2010; Van Nes, 2012). However, the different levels of dynamism will obviously affect their tangible characteristics and, more specifically, the visual elements of such living brands.

For the purpose of this paper, that would be the case of the visual element colour: corporate colours have long been one of the most prominent vectors of any VIS, being symbolically codified and meant to support certain meanings and allusions. In fact, for many brands, colour has been pivotal in terms of creating familiarity and supporting both consistency and immediate recognition, through the development of colour ownership throughout the brand's life.

Despite the enormous amount of existing information in colour theory, and the marketing research in the relevance of carefully defining the right and consistent set of colours for a brand, there is no research covering the rise of colourful brand palettes. These are not necessarily determined by a specific or prescriptive set of visual standards (Kreutz, 2005; Leitão et al., 2014) and have been implemented by several brands, mostly during the past ten years, in response to a more open, global, interactive and flexible environment.

Combined through different harmonies, colour seems to be one of the most mutable visual elements. Hence, as an exploratory foundation, the main goal for this paper was to identify the most distinctive chromatic choices of a selection of dynamic visual identities, as a preliminary step for the understanding of any patterns or shared strategies in these adaptive visual approaches. Hence, the research question is: What colour patterns emerge in dynamic brand identities?

\section{Literature Review}

It is widely recognised that brands, which are one of the most relevant manifestations of organisations and any other self-promoting entity (either a group or a single individual), are composed of several intangibles, such as the style of management, the structure, the behaviour and procedures (Lambert, 1989), values and culture, skills, assets and resources (Davidson, 1997), personality and self-image (Kapferer, 1997), but also of tangible, functional components that, altogether, form the brand's Visual Identity System (VIS), one of the strategic resources for brand's identity consistent use and systematisation: name, logo/symbol, typography, colours, slogan, signage, language (Grossman, 1994; Kapferer 1997, 2001; Mollerup, 1999; Aaker, 2004; Kreutz, 2005; Olins 2005; Keller et al., 2008, Peón, 2009; Wheeler, 2012; Van Nes, 2012; Oliveira, 2013).

Lightfoot and Gerstman (1998) group colour, symbol, shape and lettering as the main elements that contribute to what they define as visual equity, which, in the context of brands, contributes towards brand recognition (Bottomley and Doyle, 2006). However, more recently, a new wave of mutability entered the visual language of some brand identities, mostly impacting their visual equity elements, combining colours and implementing sophisticated effects, adapting their morphological aspect, distorting or transforming the typographical resources, and presenting multiple symbols, welcoming a multitude of meanings. 


\section{Colour, in theory and practice}

Colour theory is mostly grounded in optics, the branch of physics that studies the behaviour, properties and interactions of light, but in practice, there are so many uses of colour that the subject is touched on across a wide range of disciplines, making it almost impossible to establish a unique domain and taxonomy for colour.

However, in the early $20^{\text {th }}$ century, Albert Munsell proposed a rational model to describe colour, based on polar coordinates, and using a decimal notation instead of colour names (Choudhury, 2010), focusing on the representation of colour's three visible qualities: Hue, Value/Lightness and Saturation/Chroma.

Hue is the quality we use to refer to a colour on the spectrum and each hue corresponds to a single wavelength (Figure 1); in its simplest form, 'hue' is the construct we use to name colours (blue, yellow, orange, etc. as individual hues), although the traditional and common colour names are by no means enough to list all the possible hues the human eye can detect. Value (or Lightness) is the property that translates colour through its relative lightness or darkness, depending on its ability to reflect more or less light, respectively; colour value is useful to classify a hue's brightness (e.g. dark blue, light pink). Finally, Saturation, also known as Chroma, categorises colours by their purity - saturated colours are vibrant (such as "electric" blue), whereas desaturated colours are those in which two opposite hues are mixed (such as "khaki green", which is a result of mixing green with red) (Hornung, 2012; Sherin, 2012; Opara and Cantwell, 2014; Triedman, 2015).

Figure 1. The visible spectrum 
Munsell's model, which inspired the broadly agreed colour terminology within the visual arts and design fields - and which is also acknowledged by Adobe ${ }^{\mathrm{TM}}$ (Hornung, 2012) - is organised as a three-dimensional colour 'tree' and contains 10 hue families (red, yellow, green, blue and purple are the five principal hues and yellow-red, green-yellow, blue-green, purple-blue and red-purple the five intermediary hues), depicted as a spacial circle (Figure 2 ), which is grounded on the colour wheel concept (Figure 3), and that rotates horizontally around a white to black vertical axis, representing lightness. Saturation/Chroma of each colour hue is also presented horizontally, from the centre of the vertical axis, expanding beyond each hue towards its purest version. The further the colours are from the vertical axis, the more saturated they will be. Note that in Munsell's system, the 10 hue families are positioned as if they were perceptually equidistant, having equal angular spacing in between, but the Optics and Physics reality is that the natural colour space is highly irregular, and some hue families occupy a "larger" area in the colour spectrum (Figure 1). Nevertheless, whereas no geometrical device can accurately represent perceptual colour space, colour space itself would be utterly difficult to study, understand and utilise without such a simplified model (Choudhury, 2010).

Figure 2. Munsell's Colour System

(Diagram created after Munsell, 1977)

Based upon a set of hue relationships, colour harmonies (or colour combinations) may also include variations in lightness/value and in saturation/chroma. The literature (Hornung, 2012; Sherin, 2012; Opara and Cantwell, 2014; Triedman, 2015) identifies the following as the most common schemes of colour harmony (Figure 3):

Figure 3. The five most common colour harmonies, depicted on colour wheels

- Monochromatic: these colour harmonies usually rely on one single hue, but may include value/saturation variations of the same unique hue;

- Analogous: characterised by the combination of hues which lie adjacent to each other in the hue spacial circle;

- Complementary: the combination of any two hues occupying opposite positions in the spacial circle;

- Triadic: the combination of any three hues occupying equidistant positions in the spacial circle;

- Tetradic: a composition of any four hues occupying equidistant positions in the spacial circle.

Brands have been relying on these harmonies for decades, particularly the first four. Monochromatic brand identities take one colour hue (such as red) and consistently use it throughout their communication applications (e.g. Coca Cola), in some cases mixing it with white or black - in order to generate either a lighter or a darker red version of their corporate red. Analogous brand identities adopt a colour neighbourhood approach, usually having a colour as reference (such as green, in the case of BP) and using it with nearby hues (e.g. lime green, if the neighbouring colour is yellow, or mint green, if the neighbouring colour is blue). Complementary or triadic brand identities opt for a set of distinct corporate colours, 
either using two very different colours (like yellow and blue for IKEA or orange and purple for FedEx) or three undoubtedly different colours (blue, yellow and red, as in Burger King), respectively. Traditionally, these colour combinations are made in order to convey certain meanings and generate specific and easily recognisable associations.

\section{Colour association in brands}

Hornung states that "colour has an added dimension that is essential as its optical behaviour and structural parts: that is, the way it stimulates the heart and mind of the viewer" $(2012, p$. 123). The author claims that colour preferences and associations vary greatly from individual to individual, evolving over the individual's lifetime, and are also highly influenced by culture, locations and eras. Having said that, any generalisation of the meanings of colours and how they make us feel is rather difficult to obtain due to the many variables involved.

Hornung (2012) explains that there are two types of colour associations: colour symbolism and colour analogies. Colour symbolism depends greatly on the context, it is mostly associated with unique and saturated hues and can be conventionalised, as in "blue blood" to symbolise aristocracy. Colour analogies are "associations that connect the visual properties of colour with nonvisual phenomena" (2012, p. 125) such as sounds (through sound-tocolour synesthesia, or chromesthesia), tastes (such as the flavour of unripe fruit suggesting the colour green) or temperaments (when feelings are associated with specific hues, such as grey or blue for sadness).

Some researchers argue that colour relationships also have the power to provoke expected psychological effects, grounded in memory. According to Chague et al. (1998), humans perceive colours faster than they perceive shapes, icons and other symbols, making colour the most influential visual resource for facilitating brands' memorability (Caivano and López, 2006). There is also substantial research around the relationship between colour and customer's decision-making and consumer behaviour (Tan, 2011). Singh explains that a careful use of colours contributes both to the differentiation purpose and to positively or negatively influencing moods and feelings (2006, p. 783), which will have impact on a consumer's attitude and preference towards certain brands. In a comparison between utilitarian and hedonistic attributes of products and brands, Bottomley and Doyle (2006) show that the relationship between brands and colour is highly dependent of the perceived appropriateness of the colour being used for the particular type of product or brand, as they found that functional colours, such as blue, would be more appropriate for functional products, whilst sensory-social colours, such as red, would be more appropriate for sensorysocial products. Labrecque and Milne (2012) also tell us that consumer's intentions are determined by a brand's set of colours and their effect on how the consumer interprets the brand's personality. Marlboro's storytelling, for example, has been linked, for years, to brown warm hues as a means of expressing the ideal of the American West, which is masculine, rough, natural and rugged and, after decades, this became a way to personify the brand. Hence, according to the existing literature, certain colours can be aligned with specific personality traits (e.g., blue with competence, brown with ruggedness and red with excitement), defending that entities should select their brand's colours not really to align themselves to stereotypical images (which may be deterred from success by cultural factors, as there is no universal law of colours), but to support the brand personality they plan and expect to crystallise. 
In fact, some brands are strongly linked to a single colour in particular which they own, and which is part of their protected and registered logo, but that also embodies who they are or what they do (Coca Cola with red, Benetton with green), in a relationship that eases recognition (Henderson and Cote, 1998), with a subliminal persuasive power as it draws various emotional responses (Eiseman, 2000). From this perspective, brands that, within their category, own a colour in a consumer's mind should be in a better position to guarantee recognition: whilst it is widely acknowledged that McDonalds owns yellow in its category, it is not as clear which colour Burger King claims for itself. Other brands have also been associated with a multicolour approach. For example, The Olympics, with each colour ring symbolising the five continents, displays a message of both inclusivity and connection. Other iconic brands which make use of a non-owned colour approach are Apple, Google and eBay.

The associations brands aim at creating, within a specific audience and through a careful selection of colours, have been a fascinating topic for many researchers for a couple of decades. Some claim they have been able to predict such associations and aftermaths by developing methods and theories, as the case of Shigenobu Kobayashi or Angela Wright. In their works, saturated prismatic colours grouped together evoke festivity, joviality, blithely; a group of desaturated colours evoke quietness, ageing, dryness; a combination of light colours will elicit airy or fragility sensations (Kobayashi, 1981, 1990; Wright, 1998).

\section{Dynamic colour associations?}

However, these psychological connections will be increasingly more unpredictable as more colours, through semi-translucencies, overlaps and blends, are cumulatively combined, possibly exacerbating complex reactions and unexpected experiences. In these conditions, there is no absolute way to argue why choosing one colour over another will be a better option, maybe except for objective technical reasons. Nevertheless, whilst two decades ago, visual identity systems had to take into account production considerations, mostly related with print and the costly number of colours, with the advances in technology, brands can now afford to use many different hues, including value and saturation combinations, using gradients, shadowed and bright areas, simulating textures and multidimensional contexts, in a variety of different media, techniques and applications, being packaging, window display and the Web the most common (Ko, 2017; Magnier and Schoormans, 2017; Rizomyliotis et al., 2018).

Thus, while some brands are embracing a colourless approach, such as the Lincoln Center in New York because "... companies find that when you go into a vocabulary of more than three colours, it starts to look too fanciful, and they become threatened by it" (Opara and Cantwell, 2014, p. 146), others are enthusiastically adopting a strategy based on colour variety, as in the case of the paper producer Mohawk (interestingly, a case linked to the print industry), opting for not being associated with any colour in particular (Figure 4).

Figure 4 - Mohawk visual identity

(Source: $\underline{\text { www.underconsideration.com) }}$

It is believed that when a brand opts for a wide range of colour possibilities for its logo, it may be implying the diversification or globalisation of its activities, on one hand possibly exploring meanings such as inclusiveness, diversity, boundless, multimodality, ubiquity 
(Felsing, 2010) and, on the other hand, not necessarily concerned with conveying any specific personality trait nor any recognisable colour association in particular. In fact, some dynamic visual identities depend entirely on their openness to a total participatory attitude or on a specific time-bound context, such as an event, or even a non-fixed line of products/services. Examples of these are Google, with its daily doodles, virtually created by anyone; OCAD University, Canada's premier Art and Design University, in which graduates are invited to design customised imagery that will be included within the brand's basic square structure; and the cultural arena Casa da Música, in Portugal, a brand whose shape and colour change according to its temporary events, having inclusively developed a colour generator, through which a colour-picking mechanism guarantees a minimum of colour consistency. Recent studies Therefore, much is happening within the rich field of brand design, hence opening opportunities for new questions and diverse research avenues.

\section{Method}

In the case of this research, a qualitative descriptive research was elected and framed by an interpretivist and post-positivist enquiry. As opposed to positivism, the interpretivist paradigm emphasises the existence of a subjective reality, understanding the world as it is made meaningful by humans (Collins, 2010) and, drawing from this, post-positivists believe that reality exists, but it can only be imperfectly and probabilistically experienced, grounded on human conjectures (Popper, 1994).

This approach informed three content analysis studies based on the collection, comparison and scrutiny of 50 brands that are widely acknowledged as being dynamic. These were collected from the most up-to-date informal online resources of specialist knowledge (such as Underconsideration and The Branding Source websites) and from the online public and published portfolios of five major communication agencies (Pentagram, Wolff Olins, BBH, Saffron and Sagmeister \& Walsh). This, therefore, guarantees a minimum of credibility in both the strategic aspects and the design concerns of such brands. The main reason for this has to do with the results obtained with the initial exploratory search for the selection of dynamic brands, which led to several cases of mere portfolio developments which were part of freelance designers' Behance profiles, showcasing their design abilities with well-known brands' identities, or their exercises not really attached to any credible identity/institution, quite often based in fictitious brand identities. Therefore, the 50 brands under scrutiny were either developed by relevant agencies/studios or are attached to significant international cases (Table 1 and Figure 5).

Table 1 . The 50 selected brands and correspondent design studios.

Figure 5. Visual identities of the 50 selected brands

The approach is based on three studies through the analysis of these 50 brands' visual identities, verifying the changes that their colours may undergo in their numerous forms of representation, followed by the identification of their possible colour associations. Purposeful sampling was used throughout this research (both on selecting the brands and the participants).

\section{Study 1 - Matrix analysis}


The main supporting framework for this analysis was Munsell's Perceptual Colour Attributes - Hue (H), Lightness/Value (L) and Saturation/Chroma (S) - which are key for the most relevant colour harmonies - Monochromatic, Analogous, Complementary, Triadic and Tetradic (Munsell, 1977).

Since tetradic is the colour harmony that includes the highest number of hues (four), the researcher selected five visual variations of each of the 50 selected brands in order to guarantee sampling saturation. Each brand's visual variation was set against a grid, within a squared artboard. This grid is grounded on one of the most remarkable brand design supporting frameworks - the grid, which origins go back to the medieval masters and stonecutters who would use it to cut their authoring marks in Gothic buildings, and which was usually built using a $4 \times 4$ grid with a complex juxtaposition of circles on top of its horizontal and vertical central axes. The grid system has evolved, mostly influenced by modern typography, and has been traditionally used by designers;

A simplified grid of $5 \times 5$ divisions was considered the most appropriate tool for analysis, as recurring to an odd number for both columns and rows would guarantee a central column and middle row from which relevant colour samples would be most successfully picked given that 1) the logo variations would be vertically and horizontally centred/aligned within the grid; and 2) it was expected that most of the colour hues defining each variation would be concentrated in the central area of the brand's retrieved image file, and that some cases would probably have dead corners, i.e. the cells located at each corner of the matrix would have little or no colour information, except from the image own background colour (usually white). Thus, using Adobe Illustrator ${ }^{\mathrm{TM}}$, a sample of colour was picked from the geometric centre of each cell of the matrix to retrieve its hue $(\mathrm{H})$, saturation $(\mathrm{S})$ and brightness $(\mathrm{B})$ values which, together (HSB), would help on defining the prevalent hue families (Figure 6).

HSB is a variation of Munsell's colour system and is also a colour model commonly used to define colours in desktop graphics programs, as it closely matches the way humans perceive colour. Whereas in Munsell's system the attributes are hue, value/lightness and saturation/chroma, in HSB, the axes are hue, saturation, and brightness. Exactly as in Munsell's circular system, in HSB the values for the hue axis run from $0-360^{\circ}$, beginning and ending with red, due to the circularity of the underpinning system (Figure 7) and running through orange, yellow, green, blue, purple and all the intermediary colours in between. The values of saturation run from $0 \%$, which represents absolute desaturation of colour, to $100 \%$, which is the fullest saturation of a given hue. The values of brightness (corresponding to lightness in Munsell's system) are also represented as percentages: $0 \%$ means no illumination, and $100 \%$ stands for full bright light.

Figure 6 - The analysis of A1's visual identity, variation 5

Figure 7 - Circular representation of HSB colour system

As the understanding and use of the colour wheel and Munsell's circular colour space is highly dependent on knowing a certain hue value (both saturation and lightness are attributes that are used to classify a given colour hue), in order to reduce the complexity of the analysis, the approach towards a systematic arrangement of colour for this research was grounded on Judd's "desert island" experiment, in which an isolated person on a desert island arranges the pebbles around her, firstly according to their chromatic characteristics 
(Billmeyer, 1981 apud Choudhury, 2010), i.e. hue. Hence, only the distribution of hues was considered deem necessary to count the number of hue families in each brand's five visual variations; as such, the conceptual circular colour space was divided into 10 equal areas of $36^{\circ}$ each, in order to match Munsell's 10 hue families.

This same experiment was performed by a second coder, who was briefed on the project and asked to collect colour samples at the centre of each cell contained in the matrix, using the same five design/logo variations of each one of the 50 selected brands. The coder was also asked to organise the collected colour samples into hue families, following the 10 divisions of $36^{\circ}$ used by the researcher. Whilst the researcher's analysis was performed on two different screens (MacBook Air 13-inch and iMac 27-inch) that were not professionally colour calibrated, the second coder was asked to analyse the 50 visual identities in a desktop computer, in a print studio. All these computers were colour calibrated using accurate colour profiles, shared with different types of printers. The computer's screen used by the second coder was also equipped with hoods, which purpose is to deem brightness and reflections in the screen, and to reduce eye fatigue. The purpose was to verify if different conditions in the implementation of this colour picking technique would raise any meaningful discrepancies in the colour analysis results.

\section{Study 2 - Perception analysis}

To verify data accuracy in terms of form and context, a perception analysis was carried out with seven individuals, from different cultures, different backgrounds, and different age ranges (Table 2). These were asked to classify each one of the 50 visual identities against the five common colour harmonies and an additional option titled More than 4 Colours. On one A4 sheet of paper the participants would tick the match between visual identity and colour harmony using a simple dual axis table: the vertical axis listed the 50 brands' names whilst the horizontal axis presented the colour harmonies as multiple-choice options. The participants were also given a printed booklet containing the 50 visual identities and their several visual variations, accompanied by the colour harmonies as depicted in Figure 3 and a short explanation on these. They were asked to, from a blink, immediately make contact with each of the brand identities and their logo variations and note how many colours they thought each brand comprised. This aimed to provide the research with a gauge of how people see/perceive colour profusion in dynamic brands. These individuals were selected at the researcher's university campus, on the grounds that a known context would 1) ease an empathic approach, 2) minimise rejection and 3) optimise the available time.

Table 2. Sample characteristics: participants of Study 2.

\section{Study 3 - Colour association analysis}

In addition to this, the researcher assessed each visual identity in their colour associations using Kobayashi's Adjective and Colour Image Scales (Kobayashi, 1981, 1990) (Figure 8), which has traditionally been considered a useful guide for design and marketing purposes, establishing contextual associations/meanings to moods and lifestyles, helping in matching target audiences to the right brand positioning and personality: "Since a color combination is comprehended psychologically as an image, this scale makes it easier to create particular images by combining colors" (Kobayashi, 1981, p. 93). In Kobayashi's scale, every colour is defined by three attributes: warm-cool, soft-hard, and clear-grayish, which have a direct 
relationship with Munsell's Perceptual Colour Attributes, hue, lightness, and saturation, respectively.

Using the hue families' results achieved in Study 1 and the specific HSB values collected from each variation, each brand would be mapped against Kobayashi's Colour Image Scale first, and only then, if any correspondence was found between the brand's levels of consistency in colour usage and the colour harmonies in Kobayashi's Colour Image Scale, the underpinning Adjective Image Scale would be utilised to identify a set of characterising words/labels for the brands.

Figure 8 - On the left, Kobayashi's Adjective Image Scale and on the right Kobayashi's Colour Image Scale

(Source: Kobayashi, 1981)

\section{Findings}

\section{Study 1 - Matrix analysis}

Due to the current high resolution of screens and the precision imposed by both the analysis grid and the activation of Adobe Illustrator's feature Snap To (through which structural design elements, such as guides or grids, behave as magnets, pulling towards them graphic objects and/or the cursor when these approach), the results achieved by the researcher and the second coder were extremely similar, with minor colour value/lightness or saturation variations, but in every case confirming the hue families and the harmonies classification.

With the data obtained it was observed that colour in most dynamic visual identities does not follow a consistent pattern regarding its application; on the contrary, hue, value and saturation are diversely explored and, with the exception of the monochromatic approach, in which a single hue is selected and possibly used with variations of value or saturation, none of the most commonly implemented colour harmonies in brand visual identities seems to reveal a prominent or obvious strategic preference. The Triadic colour harmony is used by only one of the analysed brands. Both Analogous and Tetradic harmonies are used by two visual identities and Complementary harmonies were identified in three.

The most recurrent tactic is not considered a colour harmony per se (nor is mentioned in the literature) and can be described as an approach in which a variety of patterns, textures and complex backgrounds include multiple hues, values and saturation levels that change in the brand's diverse visual versions. These were categorised as Polychromatic harmonies. In these special cases, which represent $58 \%$ of the gathered sample (Figure 9), there is a clear graphical flexibility in terms of colour, namely because some of them represent ever evolving and adapting visual identities that depend on a certain context, such as an event, or a non-fixed line of products/services, or even the openness to a participatory attitude.

Figure 9 - Discreet proportion of colour harmonies through the 50 analysed brands

With this study, the researcher would expect to obtain an average of four (or above) hue families across the five visual variations of these special cases but the average value of hue families was 2,5 (out of the 10 possible hue families). As three hues would correspond either 
to triadic harmonies (when the hues are visibly different, occupying distinct areas in the colour wheel) or possibly to analogous harmonies (if they had a neighbouring relationship within the colour wheel), this result seemed to be unexpectedly low, given that almost $60 \%$ of the analysed cohort was classified as Polychromatic. It should be noted that $26 \%$ of the analysed brand identities were categorised as monochromatic (Figure 9) and these do not present any hue variation because they are mono-hue, hence with great impact in regard to an average calculation.

\section{Study 2 - Perception analysis}

Therefore, as it may well be the case in which identifying the average brings no additional or relevant insights to a study that was mostly and firstly triggered by colour perception, this result lead into a second study, a colour perception analysis, which produced quite diverse and interesting results. More than 4 Colours, which would correspond to the Polychromatic harmony identified in the previous study, was the colour combination that was the most selected by all participants, with the exception of one of them, Participant 3, who found more Monochromatic cases than any other (Table 3).

Table 3. Frequencies of colour harmonies, classified in both Study 1 and 2.

Five out of 50 brand identities were given the exact same classification by all participants, fully matching the one achieved on Study 1, being two of them Monochromatic and three More than 4 Colours (Polychromatic). Similarly, in five of the analysed visual identities, the colour harmony classification achieved by the matrix-based study matched the one obtained by six out of seven participants; one of them (Participant 3) presented a fairly different categorisation.

Some visual identities highlighted the complexity of perceiving colour wealth. The expected results for this study were that Monochromatic colour combinations would be the easiest to identify, given these are defined by one hue only, but also that the cases in which differentiating between several colours would represent a certain level of challenge, participants would opt for More than 4 Colours. In fact, seven brands revealed that distinguishing between Tetradic (four colour hues) and More than 4 Colours is not that straightforward, mostly when the participants were not expected to spend time counting colours. Tetradic harmonies were significantly more popular among participants then in the results achieved in Study 1, in which the same visual identities were classified as Polychromatic. In fact, we could argue that Tetradic harmonies are a special case of a Polychromatic approach.

In the case of nine visual identities that on Study 1 were categorised as Monochromatic, the participants classified them as either Monochromatic, Complementary or Analogous, a confusion somehow understandable, most likely due to the reduced number of hues in each case. The most surprising results were those in which Polychromatic harmonies, expected to be categorised either as More than 4 Colours or Tetradic, as these undoubtedly present several colour hues, were defined as Monochromatic. All these cases were reported by Participant 3.

Given the results achieved by this individual, it seemed reasonable to include in this study a short and confirmatory interview. The telephone conversation took no more than a few minutes, and produced new information: that Participant 3, a 48-year-old IT engineer, was 
colour blind, and frequently experienced difficulties in distinguishing certain hues of yellow from hues of green and in differentiating some hues of pink and neutral gray. This participant also mentioned that on seldom occasions he also finds it hard to identify red elements when the surroundings are predominately green. When asked on how this affects his experience with brands, the participant revealed his concerns, mostly in selecting clothing products, but had never seriously thought about the way he perceives the brand's colours and how much it could differ from the colour version defined by the brand itself.

\section{Study 3 - Colour association analysis}

In dynamic visual identities that use common colour harmonies with no more than three colour hues it is possible to identify overall moods or lifestyles using Kobayashi's Colour Image Scale, for example, by considering the categorisation achieved in Study 1:

- Swisscom's Complementary colour harmony, in which white was considered a background colour and red and blue are positioned in opposite positions within the colour wheel, can be classified as Warm-Soft $>$ Casual, which within the Adjective Image Scale would correspond to Showy or Stimulative (Figure 10). In fact, in their corporate identity concept document, Swisscom claims in its brand personality diagram that their characteristics are Inspiring, Innovative, Playful, Agile, Energetic, among others.

- Monochromatic UAL, which tends to be represented via black only, can be categorised as Cool-Hard $>$ Modern $>$ Metallic/Sharp, potentially under the adjectives Proper or Sophisticated (Figure 10). UAL positions its visual identity as Bold, Simple and Direct, with a consistent, conversational and authoritative tone of voice, via delivering short, smart, clear and straightforward content.

Figure 10. Initial mapping of dynamic identities over Kobayashi’s Colour Image Scale

These are the cases in which a HSB tactic was easily identifiable - either depending on solid or pure colours, common in Monochromatic cases, or when simple mixtures occur, such as in Nordkyn's set of specific colour hues with variations towards white, hence varying in value (Table 4 ).

However, with multi-coloured dynamic identities making use of a variety of HSB values it is impossible to extract any association because their colour profusion can position their logo/symbol variations in virtually every quadrant of Kobayashi's map (Figure 11). Given that this tool was designed to accommodate colour harmonies defined by groups of a maximum of three hues only, and that both in Study 1 and Study 2 the majority of the visual identities under analysis were classified as being represented by More than 4 Colours, hence Polychromatic, Kobayashi's framework seems to be limited when dealing with brands which visual representation strategies rely in complex colour schemes, actually defined by more than three hues. Therefore, while it was easy to locate Monochromatic, Analogous, Complementary and Triadic harmonies in Kobayashi's Colour Image Scale, Tetradic and Polychromatic harmonies are only proportionally represented by a light gray area, but it is impractical to position them in Kobayashi's map, as virtually these can belong to several (if not all) quadrants.

Table 4. HSB categorisation and mapping results in Study 3. 
Figure 11. Distribution of the 50 analysed brands within Kobayashi's Colour Image Scale

Following on from this, a more in-depth analysis of the collected data in all three studies revealed that colour in dynamic brand identities can be applied following one of three different hue patterns:

- Consistent Hues, in which the same hue(s) is(are) used throughout every possible variation. Via Study 1, this is verified in 18 out of 50 of the brand identities: in the Triadic, in one of the two Analogous, in all the Monochromatic and in all the Complementary cases, taking as example Swisscom, which symbolic component variations change in shape, but consistently maintain the defined colour hues (Figure 12). These would also be the cases in which Kobayashi's map could still play a relevant role in defining or anticipating colour associations.

- Distributed Hues, an approach in which the brand's visual identity can be represented by several different hues, but each distributed per logo variation, in a way that the many possible hues are split throughout the visual identity's several variations (Figure 13). This approach is adopted by 12 of the analysed brands: one of the Analogous cases, in all the Tetradic and in nine Polychromatic brand identities. This pattern also explains the low average value of hue families across the five logo variations obtained in Study 1.

- Polychromatic Variations, in which all or the majority of the logo's variations include more than four hue families (Figure 14). This only occurs in Polychromatic brand identities and it was verified in 20 of them (Figure 15). Kobayashi's framework is helpless in these cases.

Figure 12. Fixed Hues in Swisscom's visual identity Adapted from Swisscom's Corporate Design Concept (2013)

Figure 13. Distributed Hues in Queens Theatre's visual identity Source: www.pentagram.com

Figure 14. Polychromatic Variations in Philadelphia Museum of Art's visual identity Source: www.pentagram.com

Figure 15. Distribution of colour harmonies per hue pattern

\section{Discussion and Implications}

The supposition to be tested using the research question What colour patterns emerge in dynamic brand identities? is that dynamic brands may not rely on static/fixed corporate colours or are not necessarily concerned with transmitting traditional specific values or meanings through colour. The identification of a tendency, via an exercise which takes into account the principles of fashion trend forecasts, can bring insights into how brands with dynamic visual identities communicate as trends - now and in their future endeavours - and 
remind us that trends should be critically examined so that innovation remains the priority. On the other hand, identifying trends helps marketers and designers translate concepts into something physical, sensorial and yet true or authentic to the brand philosophy.

Besides the traditional approach of keeping colour consistent in every visual representation of the brand (Consistent Hues), there seems to be a tendency for dynamic brand identities to adopt colour mutations within their logo variations and, within this trend, two other patterns emerged from this research. One in which colour hues are distributed through each logo variation (Distributed Hues) and the other in which each variation includes more than four colour hues (Polychromatic Variations).

The presented research evidences that we can actually find dynamic brands using fixed corporate colours, but the majority are not absolutely concerned with setting colour palettes and are opting for different and potentially less structured harmonies, which was clearly revealed in Study 1. With this initial analysis, an additional colour harmony label is proposed for dynamic brands: Polychromatic visual identities.

Study 2, which purpose was to verify to what extent individuals perceive colour profusion in dynamic brands (and not necessarily to gauge the degree of correspondence between its results and the ones achieved in Study 1) generally confirm that this polychromatic strategy is perceived as rather common - despite the single anomaly derived from a participant who, in a later stage, was revealed to be colour blind. In fact, if this participant had been removed from the analysis (and, therefore, not brought into this paper), the results achieved in both studies would have been even more consistent. However, according to the Colour Blind Awareness Organisation, colour vision deficiencies affect approximately $8 \%$ of men across the globe (Colour Blind Awareness, 2018), raising the question that almost $10 \%$ of the world's population perceives and experiences brands' coloured elements in different (if not awkward) ways. Miller (2015) states that powerful Sticky Brands focus on the top 10\% of their potential audience, marketing to people and companies who have an immediate need for their services or products. Whilst in this context $10 \%$ seems to be a small fraction of the potential target, from the perspective that $10 \%$ can be colour blind, the figure becomes a huge slice of the population when taking globalisation strategies into account. Worryingly, branding for colour blind individuals is an area in which little research has been made.

Historically, colour choices and combinations could rely on tools such as Kobayashi's framework (in order to align a brand's vision with desirable meanings and associations) and secondly by the designers' aesthetic and functional sensitivity on how to combine the diverse hues, saturations and values the best possible way. With Study 3, this research suggests that such colour picking devices may be unfit for some dynamic brand identities, namely those in which colour is applied either via Distributed Hues or Polychromatic Variations. For these, new decision-making systems (maybe less prescriptive and more intuitive) will have to be considered and recognised. This also leads to the consideration that these brands do not express their positioning through colour ownership and predictable associations, and that polychromatic approaches may justify an exploration within the psychological field.

The author considers this paper to be a relevant contribution to the understanding of how the visual characteristics of brand identities (namely colour) are being combined, deconstructed and reassembled in different ways, where brands can be extremely appealing due to their intrinsic sensorial stimulant capacity. Following Landor's Brand Community Model (2017) colour seems to be moving away from its sacred, inviolable position, becoming an interpretive element, and, therefore, being mostly contextually dependent and relevant. 
Through multi-coloured strategies brands own all colours, in some cases diverting from an established and widely recognised identity, for the sake of inspiring experimentation and connectivity, as if multiple colour interactions were to symbolise plurality, multiculturalism, globalisation, ubiquity and customisation, constructs that become common in the current hypermodern, multifaceted, agile and fluid scene. Moreover, these approaches acknowledge, in some way, that humans experience colour in many different ways, depending on objective optical variables (such as the quality of light or even colour blindness), but also on subjective conditions (such as culture, which shifts and varies immensely in some environments), and moods, associated with feelings. At the Breathing Colour exhibition, which was open to the public at The Design Museum in London throughout the Summer of 2017, artist and designer Hella Jongerius argued that industrialisation and its processes narrowed the way we all experience colour, suggesting that today's postmodern societies are allowing infinite colour permutations, and are living with colour in a more intimate, self-expressive and personally meaningful way. As a consequence of that, some brands adopt this chameleon-like behaviour, in which, without losing their sense of identity and positioning, they take advantage of a flexible polychromatic virtue in order to adapt and respond to the environment's challenges and audiences' experiential expectations. In this sense, a relevant insight is that consistency is not, necessarily, replication or, as IBM states in Carbon's website ${ }^{1}$, “it's a harmonious uniformity", meaning users will be able to anticipate what may happen next (based on the brand's promise), and yet always be surprised.

Although this research never aimed at theory creation nor to provide brand managers, marketers and designers with a prescription, it is fair to say the presented results can alert them to the fact that brand's visual flexibility may well become a demand and that maybe users/consumers are no longer establishing relationships with brands through the traditional and expected communication and marketing resources and design processes. Hence, Singh's idea of carefully selecting colours for differentiation and to influence moods and feelings (2006), which links to Bottomley and Doyle's colour appropriateness (2006) and to Labrecque and Milne's association between a brand's colours and consumer's intentions cannot be taken as generalisations, because they have no applicability in the context of dynamic brand identities adopting polychromatic palettes. This informs the reliability of this study.

Reliability of descriptive qualitative research can be assessed through the post-positivist Popperian dictum of falsifiability, on the grounds that science cannot be fully supported on an inferential basis (Popper, 1994). According to Popper, a singular true statement such as "brands invest in colour ownership and consistency" cannot be used to affirm a universal generalised condition, because the singular observation of a brand which is not concerned with colour ownership or consistency serves to evidence that the universal statement "all brands own a colour and use it consistently" is false. Therefore, the research supposition that "There are brands that do not invest in colour ownership and consistency" implies "There is something that is a brand and that does not necessarily invest in colour ownership and consistency". It is impossible to observe all the brands in the world to verify that they all follow the colour ownership and consistency assumption (because brands are organic and living elements, constantly evolving, and equally new brands are born each day, while others expire or are subsumed and leave the market). But given that this is the traditional marketing and communicational approach, and the one we can mostly observe, previous research has been recording evidence that, in general terms, this is the case. The statement

\footnotetext{
${ }^{1}$ Carbon is the design system for IBM Cloud products: carbondesignsystem.com
} 
"all brands own a colour and use it consistently" is testable by being falsifiable. Conversely, the same would apply to "(all) dynamic brands adopt a polychromatic palette", which this research proves to be false because some dynamic brands do adopt other colour strategies.

\section{Limitations and Future Work}

This is a new and underexplored subject field and the lack of supporting empirical work in the area of dynamic brands imposed some restrictions.

Study 1 had to face imposed limitations: the $36^{\circ}$ intervals to determine each hue family in order to capture HSB codes might not have been the most rigorous measurement system, as in some cases the values would position hues as part of the Yellow-Red family, but in screen they looked much more within the green group. This may also be due to the fact that, as mentioned, the natural colour space is rather irregular and not really bound to specific angles. Choudhury (2010, p.35) states that Munsell's system, although being the most relevant and inspirational for all its successors, includes discrepancies in the perceptual spacing of colours, which vary according to where they are located in the colour cycle, adding that complementary colours do not actually occupy opposite positions in a natural colour spatial representation. The $5 \times 5$ grid may have been reductionist as well, as in some cases it did not allow the colour picker to reach hues that were positioned somewhere within a grid cell, but not at its centre, and that might have had, potentially, increased the average figures of hue families. However, it guaranteed an equal and consistent analysis of the 50 selected brands.

Study 2 was used to confirm insights achieved in Study 1 based on the perception of denoted visual elements but did not incorporate the perception of connoted ones, which could have been used to prepare Study 3, i.e. participants might have been asked for the associations/meanings they thought each dynamic brand were expecting in their audiences.

As Henderson and Cote (1998) state, colours may have impact on the way humans are cognitively stimulated, and colour harmonies are especially effective in this respect. In regard to Study 3, with polychromatic visual identities, the levels and the moments of excitation promoted by changing colours are still unknown, and the meanings/associations proposed by Kobayashi and used by marketers, designers and even Pantone ${ }^{\circledR}$ for years lose applicability in this context.

Therefore, the presented results may suggest new perspectives regarding further research. From a theoretical standpoint, it would be pertinent to research the possibility of unexplored meanings, considering that appropriate/inappropriate or acceptable/unacceptable corporate colour codes may be coming to an end, which may be related to the dissolution of communicational, cultural and ideological barriers and stereotypes. From a practical perspective, it might be relevant to:

1. better understand how polychromatic palettes can successfully be implemented without affecting a brand's recognition (which historically relied on visual consistency) and, still, establish customer loyalty; and

2. as designers become aware that brands' VIS components change, in more or less controlled ways, it is harder to translate the brand visual identity standards into traditional brand guidelines; hence the necessity in clarifying how would brand guidelines (or play books, as per the current jargon) explain the usage of polychromatic palettes for third parties to use, especially when:

a. these implicate higher print production costs, and 
b. brands increasingly allow their audiences to participate in their visual discourse.

Nevertheless, and although agreeing with Sääksjärvi et al. (2015) regarding that dynamic visual identities and logo variations can be promising resources for brand managers willing to work on brand freshness, a thorough design thinking process, including serious semiotic research, is deemed necessary in order to identify when this approach will actually be beneficial to the brand.

Within this new context there is plenty of space for other methodological approaches to be considered: it is believed that, as a continuity, this study would also benefit from an ethnographic approach, in which the audiences' perceived experience with polychromatic dynamic brands would be gathered and measured. An inferential analysis grounded on a larger sample of dynamic brands could also be considered in order to validate this first iteration. Empirical tests grounded on age, gender, colour blindness, visual literacy and cultural background might also be interesting to contemplate.

Moreover, reflections should be made in terms of the actual necessity in guaranteeing the alignment of a brand's strategy with 1) personality traits, which promise to become highly debatable as we advance towards artificial intelligence (AI), and with 2) attaining desirable meanings and associations (desirable to whom?), especially when it comes to defining engaging tactics for later $\mathrm{K}$ and Alpha generations, the so-called brand agnostics.

\section{List of References}

Aaker, D. (2004), "Leveraging the Corporate Brand", California Management Review, Vol 46 No. 3, pp. 6-18.

Bottomley, P. and Doyle, J. (2006), "The interactive effects of colors and products on perceptions of brand logo appropriateness", Marketing Theory, Vol 6 No.1, pp. 63-83.

Caivano, J. and López, M. (2006), "Chromatic Identity in Global and Local Markets: Analysis of Colours in Branding", Paper presented at the International Colour Association Congress, October 2006, Johannesburg, South Africa.

Chague, M., Mattiello, M. and Pescio, S. (2000), "ArgenColor 1998". Proceedings 4th Argentinean Congress of Colour, Grupo Argentino del Color, Buenos Aires, pp. 153-158.

Choudhury, A. (2010), "Scales for Communicating Colours", in Gulrajani, M. L. (Ed.), Colour Measurement: Principles, Advances and Industrial Applications, Woodhead Publishing, Cambridge, pp. 19-69.

Collins, H. (2010), Creative Research: the theory and practice of research for the creative industries, Bloomsbury, London.

"Colour Blind Awareness", Colour Blindness, available at http://www.colourblindawareness.org/colourblindness/ (accessed 28th April 2018).

Cruz, C. (2014), Modelo para a valorização partilhada da marca, PhD Thesis, University of Aveiro and University of Porto, Portugal.

Davidson, H. (1997), Even More Offensive Marketing - an exhilarating action guide to winning in business, Penguin Books, London.

Eiseman, L. (2000), The Pantone Guide to Communicating with Colour, Grafix Press, New York. 
Felsing, U. (2010), Dynamic identities in Cultural and Public Contexts, Lars Müller Publishers, Baden.

Grossman, G. (1994), "Carefully crafted identity can build brand equity", Public Relations Journal, Vol 50, pp. 18-21.

Henderson, P. and Cote, J. A. (1998), "Guidelines for Selecting or Modifying Logos", Journal of Marketing, Vol 62, pp. 14-30.

Hornung, D. (2012), Colour: A Workshop for Artists and Designers, Laurence King, London.

Kapferer, J. (1997), Strategic brand management: creating and sustaining brand equity long term, Kogan Page, London.

Kapferer, J. (2001), (Re)inventing the brand: can top brands survive the new market realities?, Kogan Page, London.

Keller, K., Apéria, T. and Georgson, M. (2008), Strategic brand management: a European perspective, Pearson Educated Limited, Essex.

Ko, Y-H. (2017), "The effects of luminance contrast, colour combinations, font, and search time on brand icon legibility", Applied Ergonomics, Vol 65, pp. 33-40.

Kobayashi, S. (1981), "The aim and Method of the Colour Image Scale", Color Research and Application, Vol 6 No. 2, pp. 93-107.

Kobayashi, S. (1990), Colour Image Scale, Kodansha America, New York.

Kreutz, E. (2005), Identidade Visual Mutante: uma prática comunicacional da MTV. $\mathrm{PhD}$ Thesis. Pontifícia Universidade Católica do Rio Grande do Sul, Porto Alegre, Brasil.

Kreutz, E. (2012). "Construindo marcas mutantes", Chasqui: Revista Latinoamericana de Comunicación, Vol 19, pp. 61-65. Available at: http://chasqui.ciespal.org/index.php/chasqui/article/view/120 (accessed 28th October 2017).

Labrecque, L.I. and Milne, G.R. (2012), "Exciting red and competent blue: the importance of color in marketing", Journal of the Academy of Marketing Science, Vol 40 No.5, pp. 711727.

Landor (2017), Revolutionizing the way we manage brands: The Brand Community Model, available at: https://landor.com/thinking/revolutionizing-way-manage-brands-brandcommunity-model (accessed on 16th March 2018).

Lambert, A. (1989), "Corporate Identity and Facilities Management”. Facilities, Vol 7, pp. 7-12.

Leitão, S., Lelis, C. and Mealha, O. (2014). "Marcas dinâmicas: Haverá formas de as orientar?" 1st International Congress on Brand(ing), 2-4 October 2014, ESTG, LeiriaPortugal.

Lightfoot, C. and Gerstman, R. (1998), "Brand Packaging", in Hart, S. and Murphy, J. (Eds.), Brands: The New Wealth Creators, Macmillan, Basingstoke, pp. 46-55.

Lipovetsky, G. (2007), Paradoxical happiness: Essay on hyperconsumption society. Gallimard, Paris.

Magnier, L. and Schoormans, J. (2017), "How Do Packaging Material, Colour and Environmental Claim Influence Package, Brand and Product Evaluations?", Packaging Technology and Science, Vol 30 No.11, pp. 735-751. 
Merz, M. A., He, Y. and Vargo, S. L. (2009), "The evolving brand logic: a service-dominant logic perspective", Journal of the Academy of Marketing Science, Vol 37, pp. 328-344.

Miller, J. (2015), Sticky Branding: 12.5 Principles to Stand Out, Attract Customers, and Grow an Incredible Brand, Dundurn, Toronto.

Mollerup, P. (1999), Marks of excellence: the function and taxonomy of trademarks, Phaidon, London.

Munsell, A. (1977), A Grammar of Colour. Van Nostrand Reinhold Company, New York.

Olins, W. (2008), The Brand Handbook, Thames and Hudson, London.

Oliveira, F. (2013), "Modelo/diagrama de representação dos elementos componentes da linguagem visual das marcas", BrandTrends: Journal of Strategic Communication and Branding, Vol 5, pp. 60-72.

Opara, E. and Cantwell, J. (2014), Color works: best practices for graphic designers: an essential guide to understanding and applying color design principles, Rockport Publishers, Beverley, MA.

Passarelli, B., Ribeiro, F., Oliveira, L., and Mealha, O. (2014), "Identidade conceitual e cruzamentos disciplinares", in Passarelli, B., Malheiro, A. and Ramos, F. (Eds.), Einfocomunicação: estratégias e aplicações, SENAC, São Paulo, pp. 79-121.

Peón, M. L. (2009), Sistema de identidade visual, 2AB, Rio de Janeiro.

Popper, K. (1994), Conjectures and Refutations: The Growth of Scientific Knowledge, Routledge, New York.

Rizomyliotis, I., Konstantoulaki, K. and Kostopoulos, I. (2018), "Reassessing the effect of colour on attitude and behavioural intentions in promotional activities: The moderating role of mood and involvement", Australasian Marketing Journal (in press).

Sääksjärvi, M., van den Hende, E., Mugge, R. and van Peursem, N. (2015), "How exposure to logos and logo varieties fosters brand prominence and freshness", Journal of Product \& Brand Management, Vol 24 No.7, pp. 736-744.

Singh, S. (2006), "Impact of color on marketing”, Management Decision, Vol 44 No.6, pp. 783-789.

Sherin, A. (2012), Design Elements, Color Fundamentals: A Graphic Style Manual for Understanding How Color Affects Design, Rockport Publishers, Osceola.

Swisscom (2013), Corporate Design Concept, Swisscom Brand Center, Bern.

Tan, J. (2011), Colour hunting: how colour influences what we buy, make and feel, Frame Publishers, Amsterdam.

Triedman, K. (2015), Colour: the professional's guide: understanding, appreciating and mastering colour in art and design, Ilex, Lewes.

Van Nes, I. (2012), Dinamic Identities - How to create a living brand, BIS Publishers, Amsterdam.

Wheeler, A. (2012), Designing Brand Identity: an essential guide for the whole branding team, John Wiley \& Sons, Hoboken, NJ.

Wright, A. (1998), The Beginner's Guide to Colour Psychology, Colour Affects Ltd, London. 


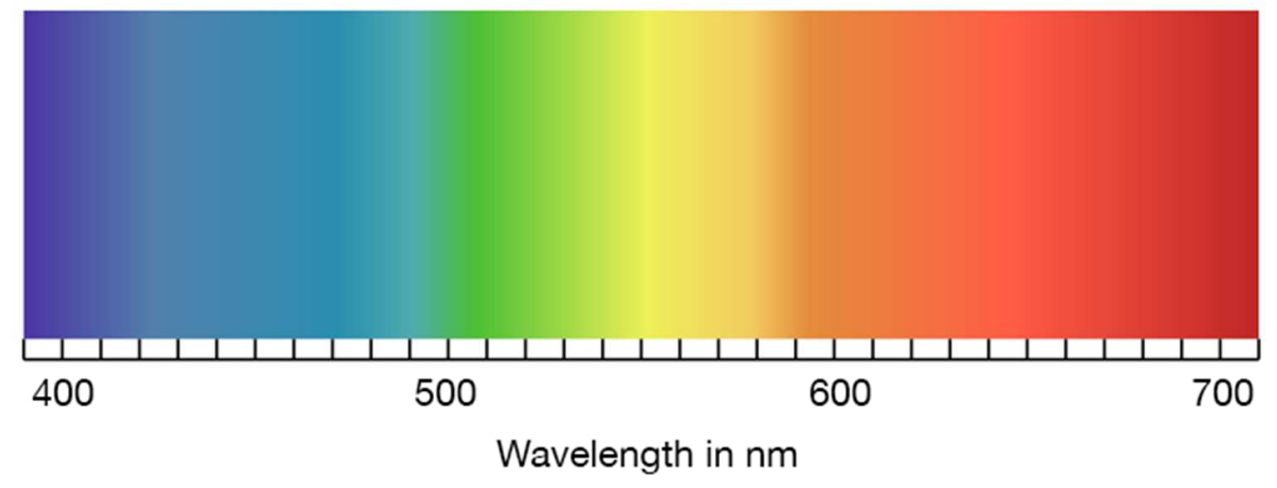

The visible spectrum $257 \times 107 \mathrm{~mm}(72 \times 72$ DPI $)$ 

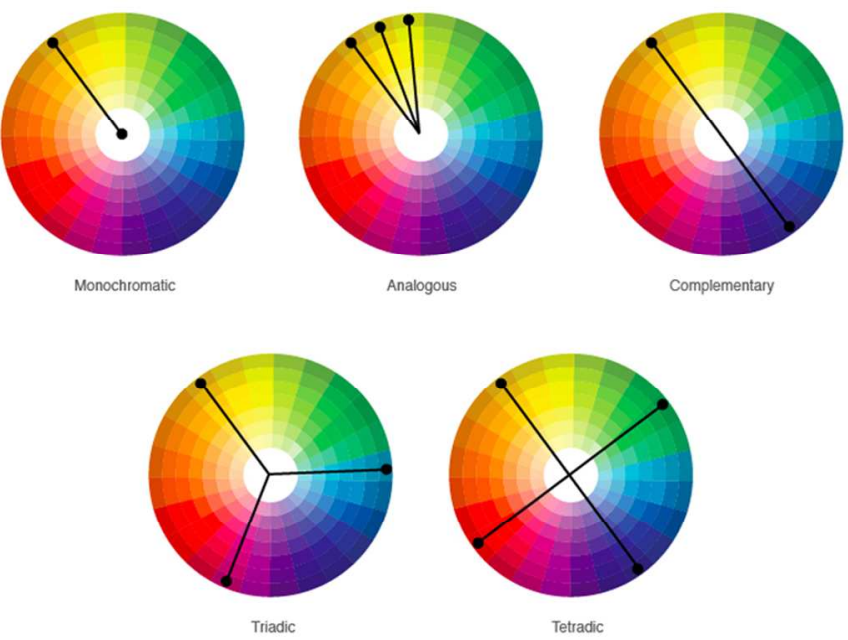

The five most common colour harmonies, depicted on colour wheels $99 \times 51 \mathrm{~mm}(300 \times 300$ DPI $)$ 

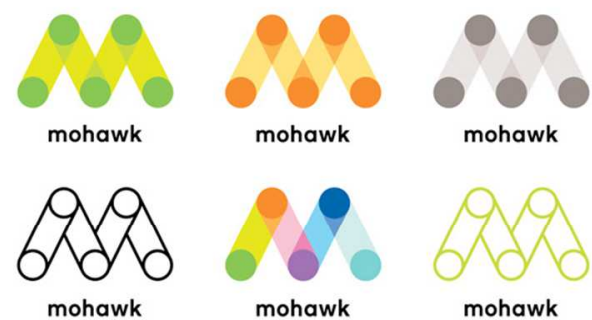

Mohawk visual identity

$99 \times 26 \mathrm{~mm}(300 \times 300$ DPI $)$ 

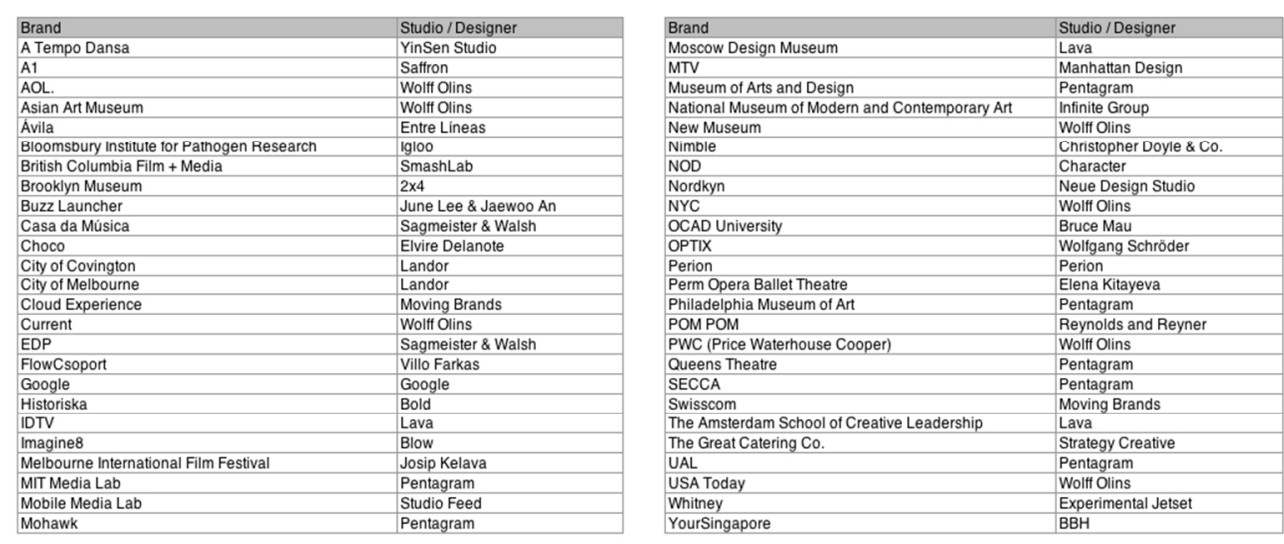

Table 1 . The 50 selected brands and correspondent design studios.

$370 \times 155 \mathrm{~mm}(72 \times 72 \mathrm{DPI})$ 


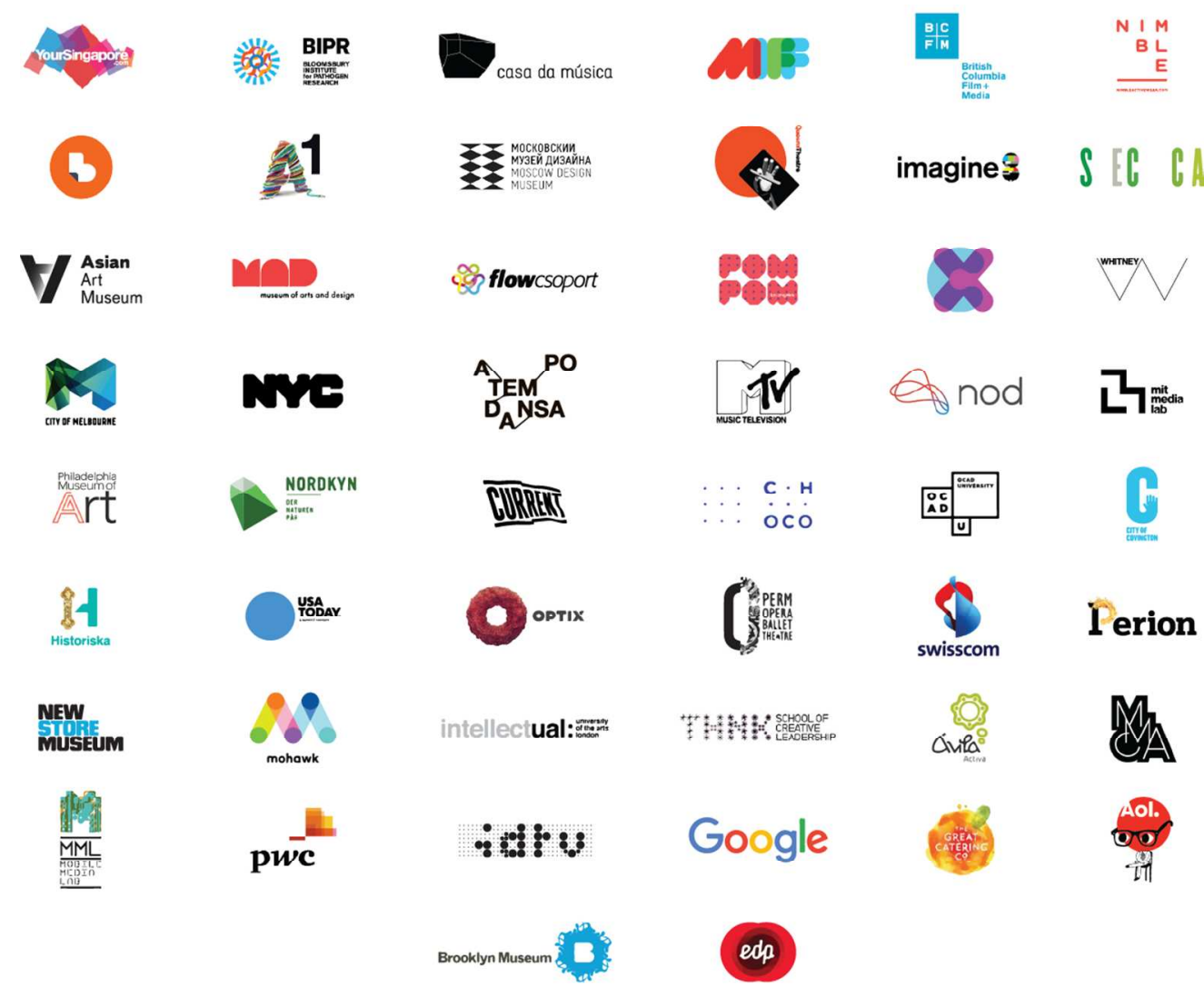

Figure 5 . Visual identities of the 50 selected brands $219 \times 181 \mathrm{~mm}(150 \times 150 \mathrm{DPI})$ 


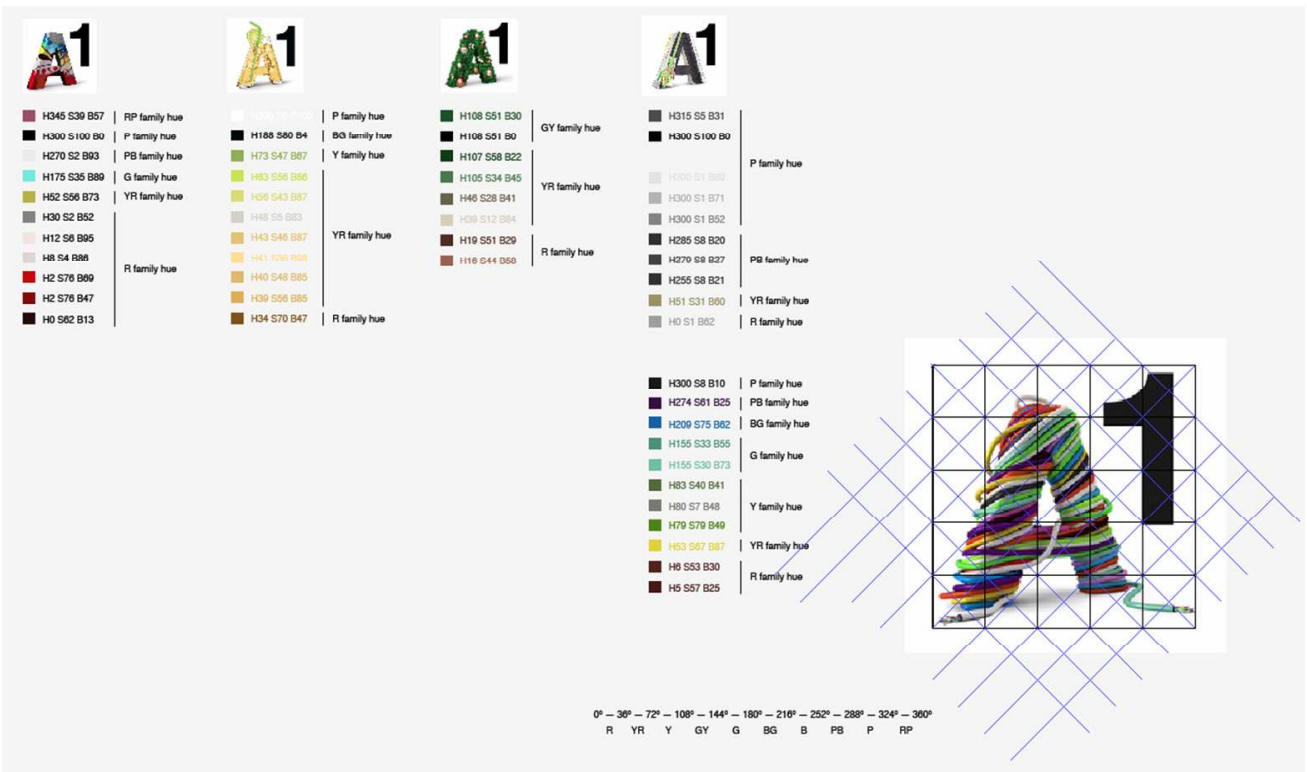

Figure 6 - The analysis of A1's visual identity, variation 5 $104 \times 61 \mathrm{~mm}(300 \times 300 \mathrm{DPI})$ 


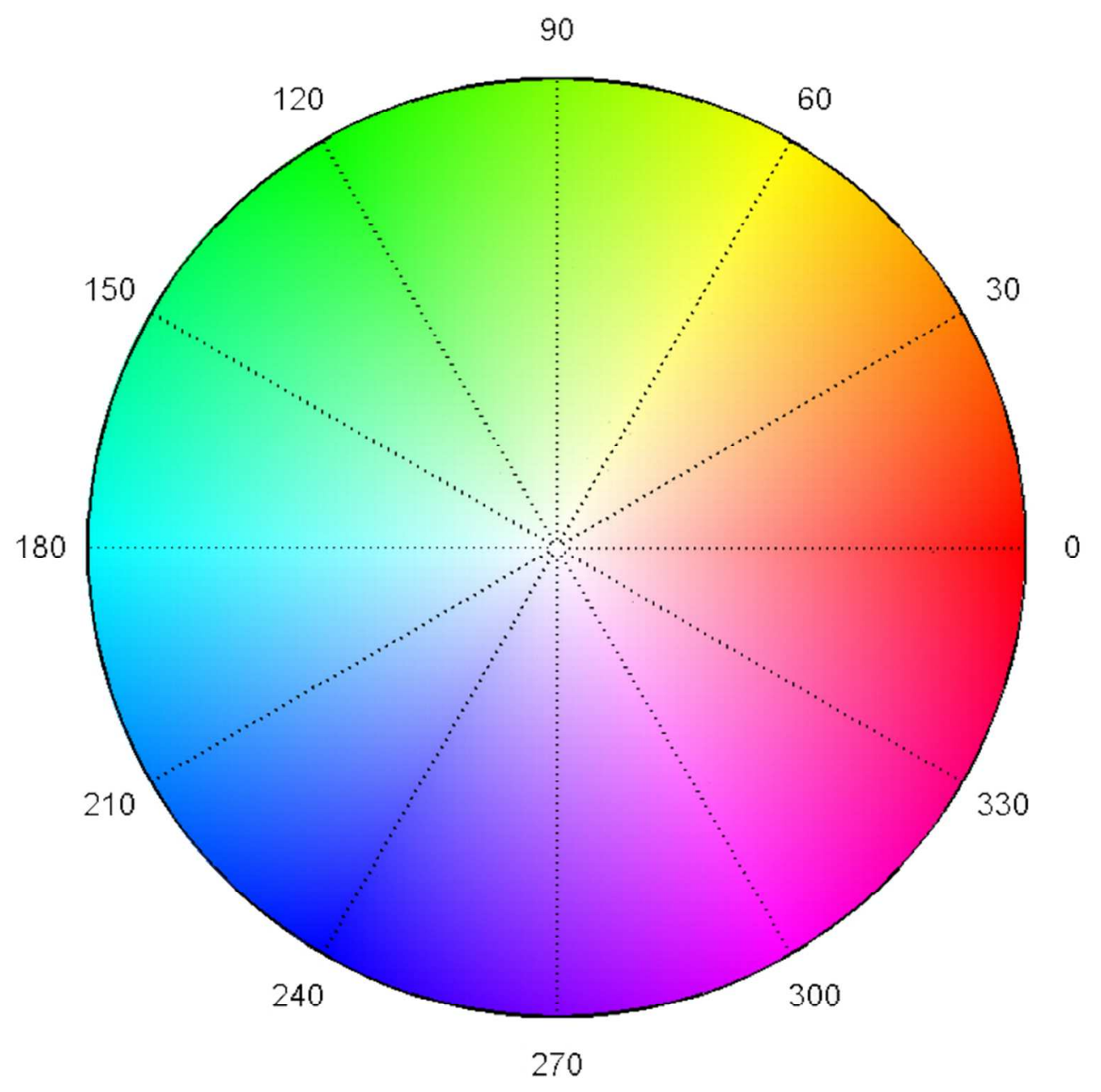

Figure 7 - Circular representation of HSB colour system $145 \times 146 \mathrm{~mm}(150 \times 150 \mathrm{DPI})$ 


\begin{tabular}{|r|c|c|c|c|c|c|c|}
\cline { 2 - 7 } \multicolumn{1}{c|}{} & \multicolumn{7}{c|}{ Study 2 } \\
\cline { 2 - 8 } \multicolumn{1}{c|}{} & Participant 1 & Participant 2 & Participant 3 & Participant 4 & Participant 5 & Participant 6 & Participant 7 \\
\hline Age & 63 & 23 & 48 & 44 & 52 & 41 & 27 \\
Gender & Male & Female & Male & Male & Female & Male & Female \\
\hline Nationality & South African & Barbados & Portuguese & Spanish & Polish & English & American (USA) \\
\hline Job/Background & Designer & Marketing Officer & IT Engineer & Sales Manager & Admin Officer & Geologist & Film Producer \\
\hline
\end{tabular}

Table 2. Sample characteristics: participants of Study 2.

$$
444 \times 60 \mathrm{~mm}(72 \times 72 \mathrm{DPI})
$$



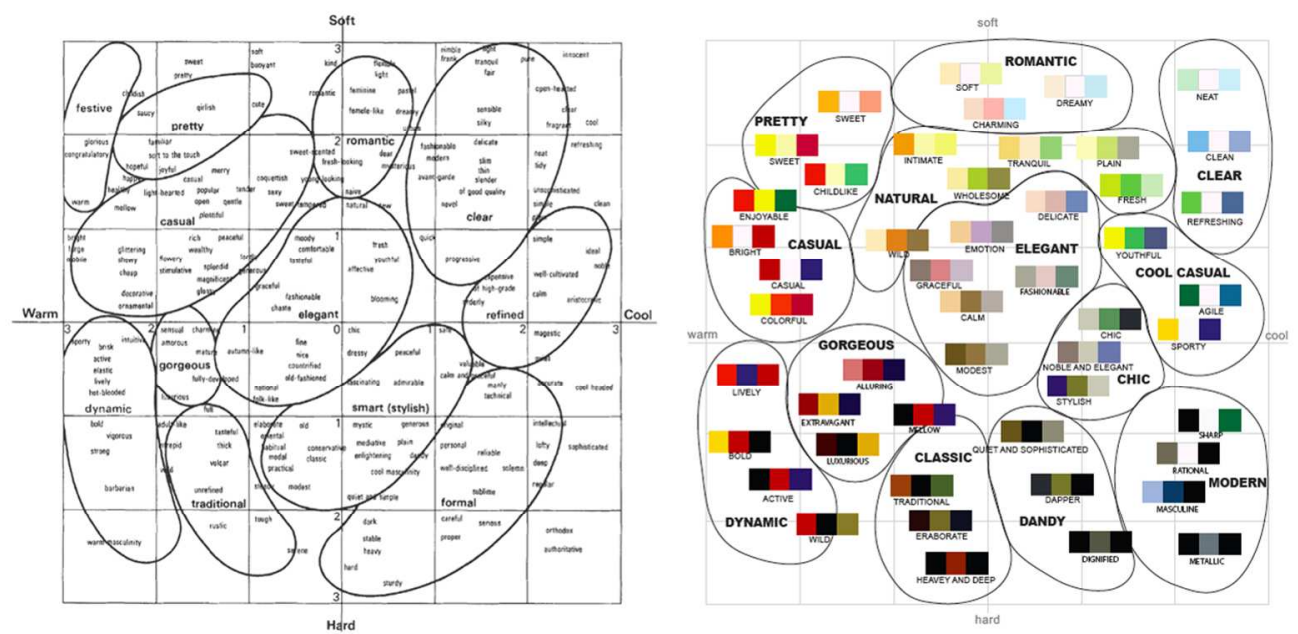

Figure 8 - On the left, Kobayashi's Adjective Image Scale and on the right Kobayashi's Colour Image Scale $106 \times 52 \mathrm{~mm}(300 \times 300 \mathrm{DPI})$ 


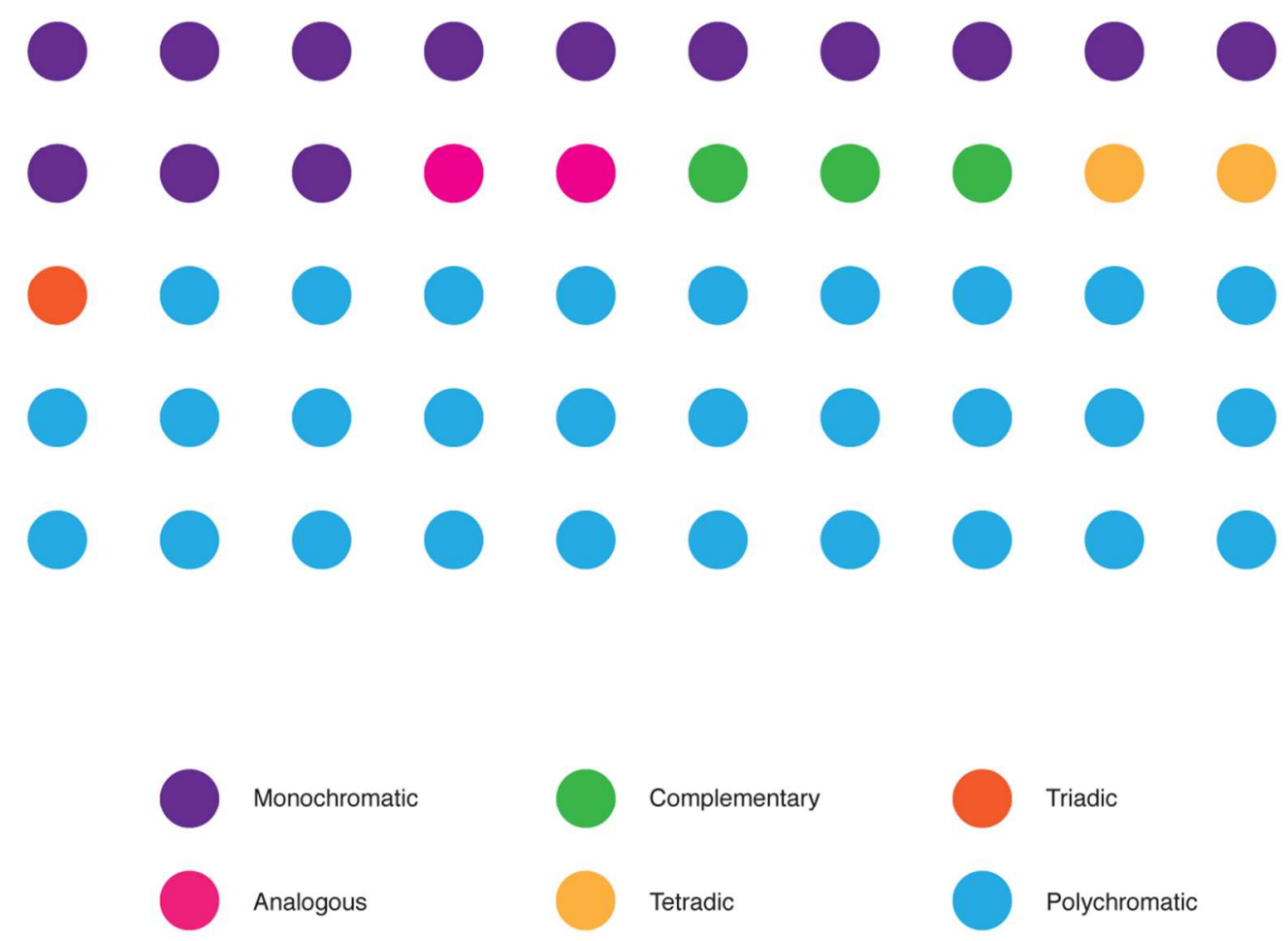

Figure 9 - Discreet proportion of colour harmonies through the 50 analysed brands $99 \times 72 \mathrm{~mm}(300 \times 300 \mathrm{DPI})$ 


\begin{tabular}{|l|c|c|c|c|c|c|c|c|}
\cline { 3 - 10 } \multicolumn{1}{c|}{} & \multicolumn{9}{c|}{ Study 2 } \\
\cline { 2 - 10 } & Study 1 & Participant 1 & Participant 2 & Participant 3 & Participant 4 & Participant 5 & Participant 6 & Participant 7 \\
\hline Monochromatic & 13 & 6 & 3 & 21 & 8 & 5 & 13 & 7 \\
\hline Complementary & 3 & 8 & 7 & 4 & 8 & 6 & 3 & 6 \\
\hline Analogous & 2 & 12 & 2 & 7 & 14 & 4 & 2 & 9 \\
\hline Triadic & 1 & 3 & 4 & 0 & 4 & 10 & 8 & 4 \\
\hline Tetradic & 2 & 3 & 8 & 3 & 2 & 9 & 7 & 11 \\
\hline Polychromatic & 29 & 18 & 26 & 15 & 14 & 16 & 17 & 13 \\
\hline
\end{tabular}

Table 3. Frequencies of colour harmonies in both Study 1 and 2.

$434 \times 92 \mathrm{~mm}(72 \times 72 \mathrm{DPI})$ 
Figure 10. Initial mapping of dynamic identities over Kobayashi's Colour Image Scale $342 \times 216 \mathrm{~mm}(300 \times 300$ DPI $)$ 


\begin{tabular}{|c|c|c|c|}
\hline \multicolumn{4}{|c|}{ Study 3} \\
\hline Brand & Colour Harmony & HSB results & Kobayashi Colour Scale \\
\hline A Tempo Dansa & Monochromatic & Hue, pure colours & Warm Hard > Gorgeous Extravagant and Dynamic Bold \\
\hline A1 & Polychromatic & Mixed HSB & Undefined \\
\hline AOL. & Polychromatic & Mixed HSB & Undefined \\
\hline Asian Ar Museum & \begin{tabular}{|l|l|} 
Polychromatic \\
\end{tabular} & Mixed HSB & Undefined \\
\hline Avila & Polychromatic & Mixed HSB & Undefined \\
\hline Bloomsbury Institute for Pathogen Research & Polychromatic & Mixed HSB & Undefined \\
\hline British Columbia Film + Media & Polychromatic & Mixed HSB & Undefined \\
\hline Brooklyn Museum & Monochromatic & Value, mixed with white & Cool Soft > Clear Clean \\
\hline Buzz Launcher & Polychromatic & Mixed HSB & Undefined \\
\hline Casa da Música & \begin{tabular}{|l|l} 
Polychromatic \\
\end{tabular} & Mixed HSB & Undefined \\
\hline Choco & Monochromatic & Value, mixed with shades & Cool Soft > Casual Sporty and Chic Stylish/Elegant \\
\hline City of Covington & Monochromatic & Value, mixed with shades & Cool Soft > Clear Clean ans Cool Hard > Modern Masculine \\
\hline City of Melboume & Polychromatic & Mixed HSB & Undefined \\
\hline Cloud Experience & Polychromatic & Mixed HSB & Undefined \\
\hline $\begin{array}{ll}\text { Current } \\
\end{array}$ & Monochromatic & Hue, pure colours & Cool Hard > Modern Metallic/Sharp \\
\hline EDP & Monochromatic & Hue and Value (mixed with shades) & Warm Hard > Dynamic > Lively \\
\hline Flowcsopon & Polychromatic & Mixed HSB & Undefined \\
\hline Guovile & Polyctirumatic & Mixed HSB & Unidefined \\
\hline Historiska & Polychromatic & Mixed HSB & Undefined \\
\hline IDTV & Monochromatic & Hue and Value, mixed with white & Cool Hard > Modern > Metallic \\
\hline Imagine8 & Polychromatic & Mixed HSB & Undefined \\
\hline Melboume Intermational Film Festival & Polychromatic & Mixed HSB & Undefined \\
\hline MIT Media Lab & Monochromatic & Hue, pure colours & Cool Hard > Modern Metallic and Dandy Dignified \\
\hline \begin{tabular}{|l|} 
Mobile Media Lab \\
Mohawk \\
\end{tabular} & $\begin{array}{l}\text { Triadic } \\
\text { Polychromatic }\end{array}$ & $\begin{array}{l}\text { Saturation, mixed with complement } \\
\text { Mixed HSB }\end{array}$ & $\begin{array}{l}\text { Warm Hard > Gorgeous > Extravagant and Natural }>\text { Wholesome } \\
\text { Undefined }\end{array}$ \\
\hline Moscow Design Museum & Monochromatic & Hue, pure colours & Cool Hard > Modern > Metallic \\
\hline MTV & Polychromatic & Mixed HSB & Undefined \\
\hline Museum of Arts and Design & Polychromatic & Mixed HSB & Undefined \\
\hline National Museum of Modem and Contemporary Ar & Polychromatic & Mixed HSB & Undefined \\
\hline New Museum & Polychromatic & Mixed HSB & Undefined \\
\hline Nimble & Monochromatio & Saturation, mixed with complement & Warm Soft > Caoual Caoual and Natural Wild \\
\hline NOD & Complementary & Hue, pure colours and Saturation & Warm Soft > Casual Casual and Warm Hard > Dynamic Active \\
\hline Nordkyn & Analogous & Hue and Value, mixed with white & Center Soft > Elegant and Natural \\
\hline NYC & Polychromatic & Mixed HSB & Undefined \\
\hline OCAD University & \begin{tabular}{|l} 
Polychromatic \\
\end{tabular} & Mixed HSB & Undefined \\
\hline OPTIX & Polychromatic & Mixed HSB & Undefined \\
\hline Perion & Polychromatic & Mixed HSB & Undefined \\
\hline Perm Upera Ballet Theattre & Polychromatic & Mixed HSB & Undefined \\
\hline Philadelphia Museum of Art & \begin{tabular}{|l} 
Polychromatic \\
\end{tabular} & Mixed HSB & Undefined \\
\hline POM POM & \begin{tabular}{|l|l} 
Polychromatic \\
\end{tabular} & Mixed HSB & Undefined \\
\hline PWC (Price Waterhouse Cooper) & \begin{tabular}{|l|l|} 
Analogous \\
\end{tabular} & Saturation, mixed with complement & Warm Soft > Casual Colorful and Natural Wild \\
\hline Queens Theatre & Tetradic & Hue, pure colours & Warm Soft $>$ Casual \\
\hline SECCA & Monochromatic & Saturation and Value, mixed with white & Cool Soft >CChic Chic and Casual Youthful and Natural Fresh \\
\hline Swisscom & Complementary & $\begin{array}{l}\text { Hue, mixed value and saturation } \\
\end{array}$ & Warm Soft $>$ Casual $>$ Casual and Warm Hard $>$ Dynamic $>$ Liv \\
\hline The Amsterdam School of Creative Leadership & Complementary & Hue, pure colours & Warm Soft $>$ Casual $>$ Casual and Warm Hard $>$ Dynamic $>$ Lin \\
\hline The Great Catering Co. & Tetradic & Hue, pure colours & Warm Soft > Pretty and Casual \\
\hline & Monochromatic & Hue and Value, mixed with white & Cool Hard $>$ Modern $>$ Metallic \\
\hline USA Today & Polychromatic & Mixed HSB & Undefined \\
\hline Whitney & Monochromatic & Hue, pure colours & Cool Hard > Modern > Metallic \\
\hline YourSingapore & Polychromatic & Mixed HSB & $\mid \begin{array}{l}\text { Undefined } \\
\end{array}$ \\
\hline
\end{tabular}

Table 4. HSB categorisation and mapping results in Study 3.

$326 \times 263 \mathrm{~mm}(72 \times 72 \mathrm{DPI})$ 
Figure 11. Distribution of the 50 analysed brands within Kobayashi's Colour Image Scale $259 \times 262 \mathrm{~mm}(72 \times 72 \mathrm{DPI})$ 



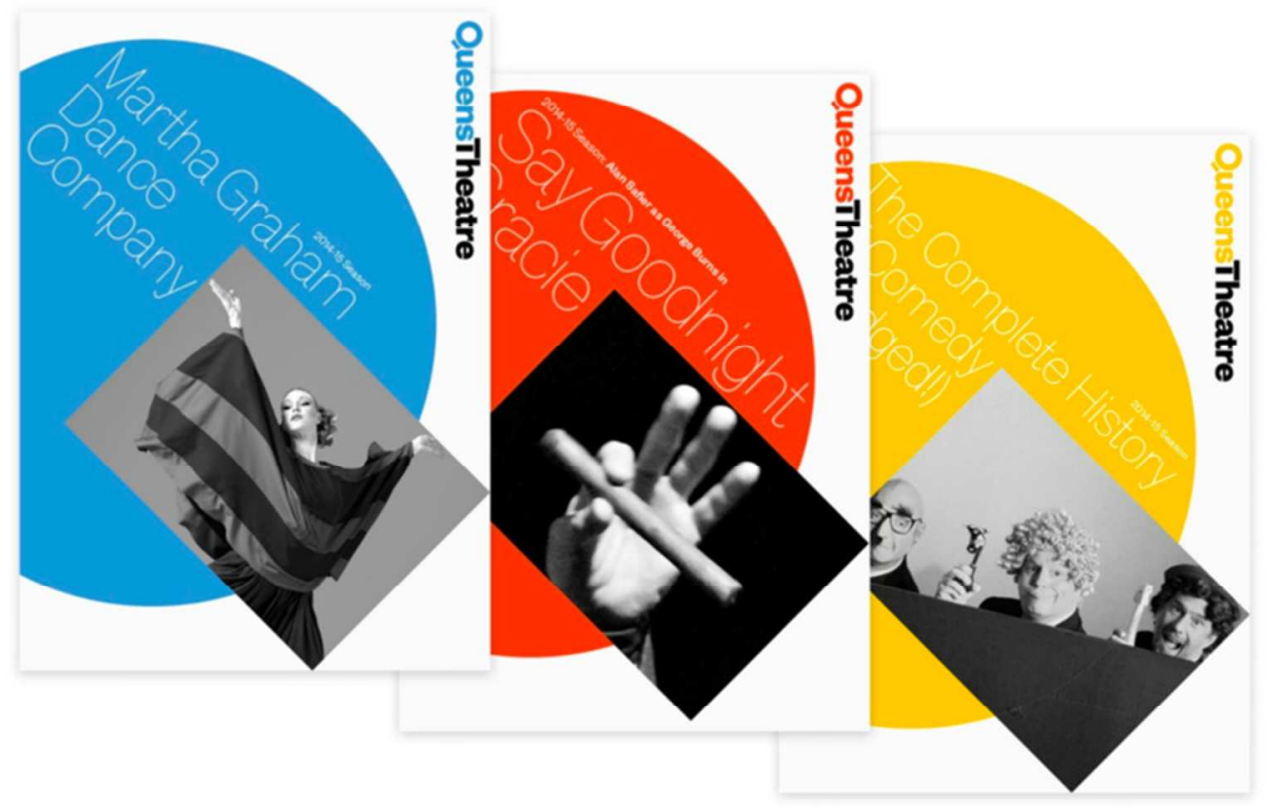

Figure 13. Distributed Hues in Queens Theatre's visual identity $331 \times 213 \mathrm{~mm}(72 \times 72 \mathrm{DPI})$ 


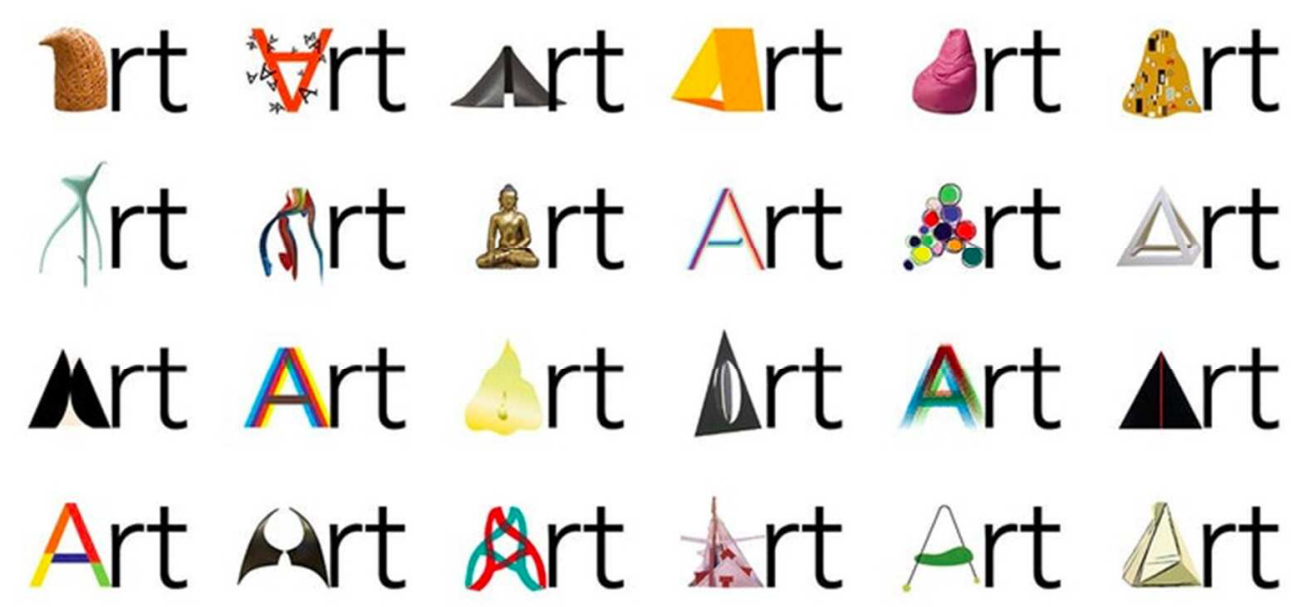

Figure 14. Polychromatic Variations in Philadelphia Museum of Art's visual identity 257x119mm (72 x 72 DPI) 


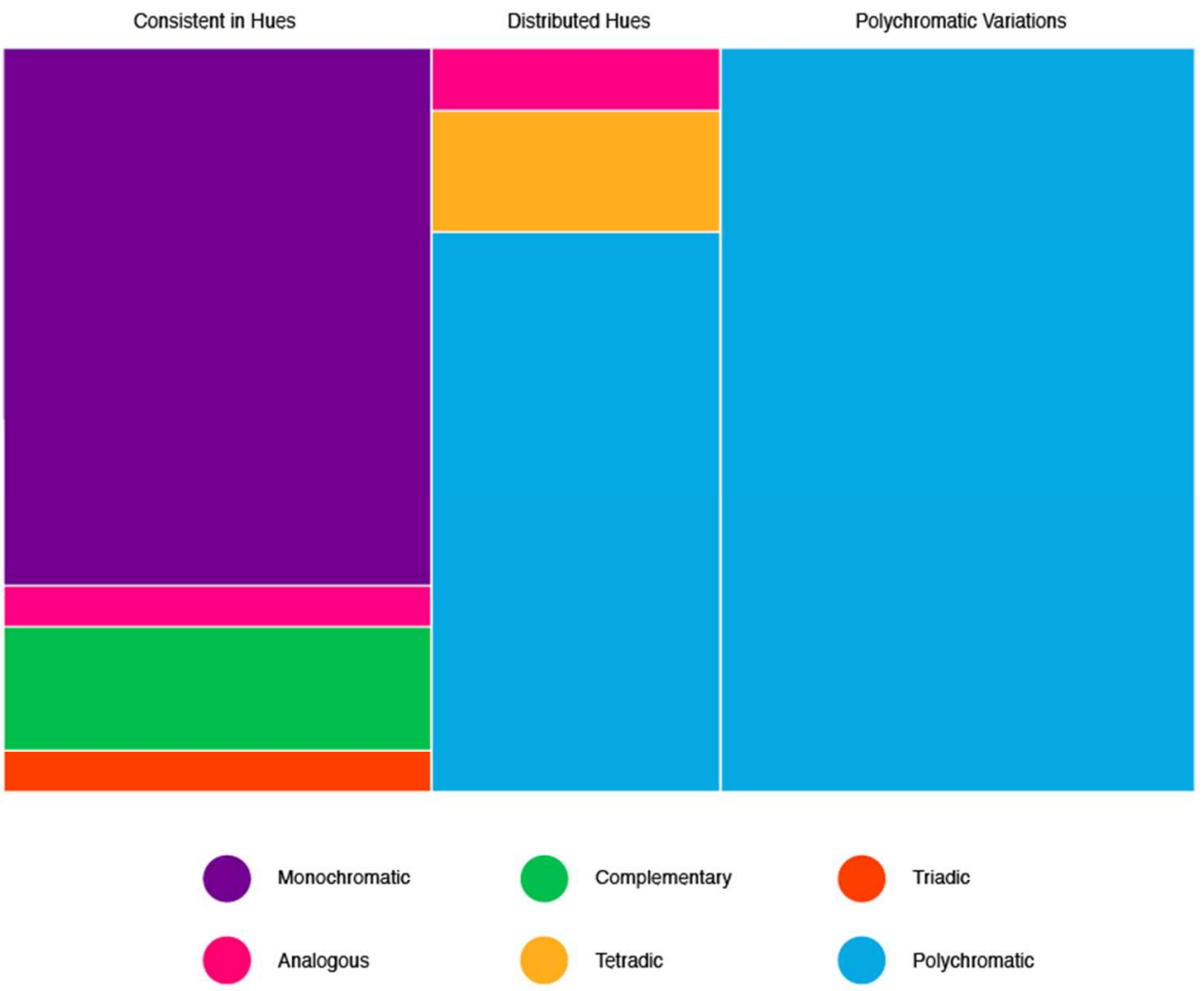

Figure 15. Distribution of colour harmonies per hue pattern $298 \times 245 \mathrm{~mm}(72 \times 72 \mathrm{DPI})$ 